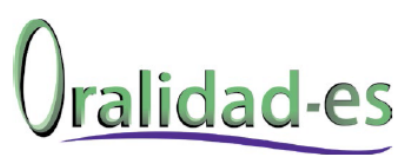

\title{
Las huellas de La Moledora: evidencias narrativas de un imaginario precolombino en la actual sociedad de los Pastos
}

\section{The traces of La Moledora: narrative evidence of a pre- Columbian imaginary in the current society of Los Pastos.}

\author{
Edison Duván Avalos-Flórez \\ duvanflo@yahoo.com \\ Instituto Tecnológico Superior "Vicente Fierro", \\ Ecuador \\ Luis Felipe Vásquez-Narváez \\ lvasquez1958@hotmail.com \\ Investigador independiente, Ecuador
}

Avalos-Flórez, E. D. \& Vásquez-Narváez. L. F. (2017). Las huellas de La Moledora: evidencias narrativas de un imaginario precolombino en la actual sociedad de los Pastos. Oralidad-es, 3(6), 28-37.

https://revistaoralidad-es.com/index.php/ro-es/article/view/84

Fecha de recepción: 20 de marzo de 2017 / Fecha de aprobación: 14 de noviembre de 2017 


\section{Resumen}

La Moledora, el último mito que permanece vigente en la tradición oral de los Pastos en la frontera colombo-ecuatoriana, presenta en su contenido algunos elementos narrativos que pueden provenir de un imaginario precolombino. Entre esos elementos se encuentra la construcción del subtrópico como un territorio asociado a la muerte y la destrucción, la concepción del mundo a partir de una organización dual, y la importancia social de los mindaláes representados por los viajeros que se dedican al intercambio de productos. Esta tesis implica aceptar que La Moledora, aunque es reactualizada cada vez que es narrada por los indígenas Pastos, conserva en su contenido narrativo modelizaciones culturales que permanecen invariables.

Palabras clave

La moledora; indígenas Pastos; tradición oral; frontera colombo-ecuatoriana

\section{Abstract}

La Moledora, the last myth that remains in the oral tradition of the Pastos on the Colombian-Ecuadorian border, presents in its content some narrative elements that may come from a pre-Columbian imaginary. Some of these elements are the construction of the subtropics as a territory associated with death and destruction, the conception of the world from a dual organization, and the social importance of the mindaláes represented by the travelers who are dedicated to the exchange of products. This thesis implies accepting that La Moledora, although it is updated every time it is narrated by the indigenous Pastos, conserves in its narrative content cultural models that remain invariable.

Key words

La Moledora; Pastos indigenous people; oral tradition; Colombian-Ecuadorian border 


\section{Introducción}

La Moledora es quizás el último relato mítico que permanece vigente en la tradición oral de los indígenas Pastos, específicamente entre aquellos que habitan en la frontera colombo-ecuatoriana, en la Comuna Agrícola la Esperanza, en Ecuador, y el Resguardo Indígena de Chiles, en Colombia. Por supuesto, las personas del sector, especialmente los ancianos, relatan muchas otras historias que hacen parte de su tradición oral, pero todas esas historias obedecen exclusivamente a experiencias personales, anécdotas de aquellos momentos en que vieron lo que ellos denominan como los seres del otro mundo. En cambio, cuando narran La Moledora logran independizarse de la vivencia personal, y crean un relato que involucra el pasado y el devenir de la comunidad.

De acuerdo a Eliade (1991), un mito es "una historia verdadera que ocurrió en el comienzo del Tiempo y que sirve de modelo al comportamiento de los seres humanos" (p. 2). En ese sentido, el objetivo de este texto es indagar cuál es ese modelo de comportamiento que La Moledora en su contenido le propone al pueblo Pasto, pero, especialmente, cuál es ese modelo de comportamiento que puede entenderse como huella proveniente de una época remota, esa herencia ancestral que los Pastos actuales reciben de sus antepasados precolombinos a través de la tradición oral. Para ello, se interpretará el contenido narrativo de tres versiones de La Moledora narradas por indígenas Pastos: una versión relatada por Oswaldo Hernán Chiles Tarapués a sus 68 años, en la Comuna Agrícola la Esperanza (Vásquez \& Avalos, 2014); otra versión relatada por Reinaldo Arteaga a sus 71 años, en el Resguardo Indígena de Chiles (Campo, 2009); y la tercera versión contada por Jorge Gonzalo Mejía Olivo a sus 88 años, en la parroquia ecuatoriana de Maldonado (Vásquez \& Avalos, 2013). Las dos primeras versiones corresponden a la zona del páramo; la tercera, a la del subtrópico.

\section{El ataque de los caníbales}

La versión de La Moledora relatada por Oswaldo Chiles, del páramo, arranca con un hecho trágico que sucedió en el subtrópico. Allá, los habitantes de una población llamada Quinyul, donde todos eran caníbales, empezaron a comerse a las personas de los pueblos vecinos, hasta prácticamente acabar con los demás habitantes del subtrópico. Cuando ya no tuvieron a quien comerse, decidieron salir en busca de nuevas poblaciones para saciar su hambre. El camino que tomaron fue subiendo por las montañas, rumbo hacia el páramo.

Sin embargo, alguien alertó a los habitantes del páramo sobre el peligro que se avecinaba. Todos se reunieron con el sacerdote para buscar una pronta solución. Lo que se les ocurrió fue dar una misa en la Laguna de la Puerta, a la cual, acto seguido, le arrojaron dos quintales de sal. De inmediato empezó a formarse una nevazón que arrasó con los Quinyules caníbales cuando pasaron por ahí. "Los que alcanzaron a manejar las plantas que traían, entre todas, coca principalmente, se hicieron halcones, águilas, osos, para poder resistir la nevazón. Los que no alcanzaron murieron en la nevazón o tuvieron que regresarse a Quinyul" (Vásquez \& Avalos, 2014, p. 28), relató Oswaldo Chiles.

Entre los Quinyules sobrevivientes se encontraba un hombre y una mujer que eran hermanos y tenían poderes sobrenaturales. Él, abandonando toda costumbre caníbal, se instaló en el páramo para convivir con los demás habitantes. Ella, por el contrario, fortaleció su ethos caníbal quedándose a vivir en la ceja de la montaña para comerse a los habitantes del páramo, quienes constantemente pasaban por ahí cuando se trasladaban hacia el subtrópico llevando papas y mellocos. Así pasó a llamarse La Moledora.

Existe en la tradición oral otro relato que recrea un ataque muy parecido al perpetrado por los Quinyules caníbales. En ese relato, que ha sido 
intitulado "La mamita de Quinyul" (Ortiz \& Vásquez, s.f) o "La Virgen de la Natividad" (Avalos et al, 2011), una horda de indios bravos del subtrópico invadió la población de Quinyul. Ahí arrasaron las viviendas, incendiaron la iglesia, mataron a quienes se les atravesaron y luego comieron la carne de sus víctimas, entre las cuales estaban algunos indígenas pacíficos, el sacerdote que los evangelizaba y varios ciudadanos españoles que dirigían la explotación minera. Las únicas sobrevivientes fueron algunas monjas que quedaron bajo la vigilancia de los indios bravos, pero, aprovechando un descuido de ellos, huyeron llevando a lomo de mula tres reliquias que encontraron intactas en las ruinas de la iglesia: dos campanas y una imagen de la Virgen de la Natividad.

Al percatarse de la fuga, los indios bravos salieron en persecución de las monjas. Ellas, para aligerar el paso, dejaron en Mayasquer una campana y la imagen de la Virgen de la Natividad, reliquias que, de acuerdo a la tradición oral, se encuentran actualmente en la iglesia de ese lugar (Ortiz \& Vásquez, s.f, p. 191). De inmediato, emprendieron su camino con una sola campana hasta el páramo, a la población colombiana de Chiles, donde informaron lo acontecido. Algunos indígenas del lugar les ayudaron a proseguir su camino hacia Tulcán, para dejar la campana en la iglesia Catedral, lugar en que, según la tradición oral, se encuentra actualmente (Avalos et al, 2011, p. 132). Otros indígenas fueron a la Laguna de la Puerta y le lanzaron sal, lo que provocó una tormenta de granizo y vientos helados que mató de frío a los indios bravos cuando pasaron por ahí. Solo dos brujos poderosos lograron sobrevivir: “[...] el uno se convierte en loro y se pierde en el cielo, el otro se convierte en lombriz y se pierde en la tierra” (Avalos et al, 2011, p. 133).

Este relato muestra a unos indios bravos muy parecidos a los indígenas Quinyules de La Moledora. Ambos grupos provienen de las profundidades del subtrópico, tal vez de las llanuras selváticas de la Costa Pacífica. Ambos llegan a los pueblos del subtrópico como una horda de caníbales que arrasan lo que encuentran, pero luego son derrotados en el páramo por una fuerza natural que se desata cuando sus enemigos le echan sal a la Laguna de la Puerta. Del mismo modo, en ambos grupos hay dos integrantes revestidos de poder que se salvan de morir: en los indios bravos, los dos brujos; y en los Quinyules, La Moledora y su hermano. Y, como si fuera poco, estas dos parejas salvadas de la muerte coinciden en que cada una está compuesta por fuerzas opuestas: La Moledora y su hermano, con las posiciones antagónicas que asumen respecto a la comunidad; y los brujos, con la oposición entre el animal aéreo y el animal subterráneo. Estas coincidencias, más allá de mostrar que los indios bravos y los Quinyules son un mismo personaje con una poderosa presencia en el imaginario social, reflejan una tensión histórica entre el páramo y el subtrópico. Esa tensión, de acuerdo a varias investigaciones históricas, empezó en 1601, cuando el cacique García Tulcanaza, de la cultura Pasto, asentada principalmente en el páramo, apoyó con cien indígenas a las tropas españolas que iban a explotar las minas de oro y plata descubiertas en el río Plata, en el subtrópico. Dos años después, en 1603, las enfermedades, las picaduras de los moscos, las inclemencias del clima, lo inhóspito de la selva, habían reducido el grupo de indígenas a apenas diez. "Prontamente se resolvió no pedir más indios de tierra fría para enviarlos a las zonas calientes de Chical y Quinchul por las razones anotadas" (Tapia, 1996, p. 75).

Indudablemente, este hecho debió generar en las sociedades del páramo y del subtrópico un distanciamiento mutuo. Los del páramo debieron crear en su imaginario un concepto terrible del subtrópico, como un lugar donde estaban irremediablemente condenados a morir en medio de terribles padecimientos. Así mismo, las sociedades del subtrópico debieron asociar en su imaginario a los indígenas del páramo con la debilidad y el apoyo subordinado a los españoles, sus principales enemigos. 
La tensión entre ambas zonas debió agudizarse aún más diez años después, en 1614, cuando otro grupo de indígenas del páramo fue enviado nuevamente al subtrópico para realizar la explotación minera bajo el mando de las tropas españolas. Ese nuevo grupo fue atacado en la población de Chical por los indígenas rebeldes provenientes de las llanuras selváticas de la Costa Pacífica. Estos indios bravos (Moya, 1999) o bárbaros de la zona de Barbacoas Alta (Tapia, 1996) tenían el propósito de acabar con los españoles y con la mano de obra indígena proveniente del páramo. En su ataque "causaron la muerte de cuatro españoles, varios indios y numerosos daños que dejaron ambre [sic] y miseria en esta parte de mi doctrina y religión” (p. 99), escribió fray Mateo Morales en el informe que entregó a la Audiencia de Quito, de acuerdo al documento citado por Tapia (1996). Al llegar las noticias de este ataque al páramo, los indígenas ya no solamente debieron sentir que la naturaleza del subtrópico les era adversa, sino también sus habitantes.

Es probable que ese ataque lanzado por los indígenas del subtrópico o de la Costa Pacífica contra los indígenas del páramo haya dado origen a lo que actualmente se cuenta de los Quinyules o de los indios bravos desde la tradición oral. Esto implica que un hecho ocurrido hace cuatrocientos años aún se mantiene vigente en el imaginario social, con la versión de La Moledora contado por Oswaldo Chiles y con los relatos "La mamita de Quinyul” o "La Virgen de la Natividad".

\section{Las dos fuerzas del origen}

La versión de Oswaldo Chiles, del páramo, presenta a La Moledora como un ser proveniente de las profundidades del subtrópico o de la Costa Pacífica, una mujer que hacía parte de los indios que impusieron una resistencia feroz al conquistador. Ella no es propia del páramo: llegó ahí proveniente desde esa otra región para ocasionar daño. Es una suerte de residuo que queda después de que los habitantes del páramo acabaron con las hordas de Quinyules caníbales. Pero no es una caníbal cualquiera: tiene poderes sorprendentes, puede transformarse a partir del dominio de las plantas, y está revestida de una sabiduría que la sitúa como líder de su pueblo.

En la versión de Reinaldo Arteaga (Campo, 2009), también oriundo del páramo, el origen de La Moledora es distinto, aunque guarda algunos pocos aspectos de similitud. Ahí también aparecen los dos hermanos caracterizados como personas sabias que practican las artes de la hechicería, y se indican sus nombres propios: él, taita Maiquer; ella, mamá Gabriela. Mas nunca se deja entrever que formen parte de un grupo caníbal asentado en el subtrópico. Solo se indica que él tenía cultivos de maíz, caña, arracacha, camote y frijol en el subtrópico, en las orillas del río Cainacán; mientras ella los tenía de papa, habas, cebada y mellocos en el páramo, en el sector de El Cascarillo.

Un día, una helada arrasó con todos los cultivos del páramo, excepto con los de mamá Gabriela. Nada en el texto insinúa que ella, con sus poderes, fuera la causante de ese fenómeno climático; al contrario, lo que se indica explícitamente es que ella, frente a esta situación, les proporcionó alimentos a todas las personas del páramo, quienes iban hasta su cementera a adquirir lo que necesitaban. El taita Maiquer, al ver lo que hacía su hermana, sintió envidia porque a su huerto nadie llegaba a solicitarle nada: por eso fue hasta los cultivos de ella y, con poderes sobrenaturales, los destruyó, dejando inhabilitada la tierra para la siembra. Logró así que las personas del páramo empezaran a ir hasta su huerto en busca de alimentos. Su hermana, debido a esta injusticia, decidió vengarse: empezó a comerse a las personas del páramo que necesariamente tenían que pasar por donde ella vivía para poder llegar hasta donde su hermano. De este modo mamá Gabriela se transformó en La Moledora (Campo, 2009). 
Tanto en esta versión de Reinaldo Arteaga como en la de Oswaldo Chiles, el origen de La Moledora está determinado por un mismo fenómeno que, sin embargo, se presenta de manera inversa. Se trata de que ella, en un caso, muestra una transformación de su interior pero una inmutabilidad de su exterior; mientras en el otro caso muestra una transformación de su exterior pero una inmutabilidad de su interior.

En la versión de Oswaldo Chiles, el interior permanece inmutable mientras el exterior se transforma. Porque La Moledora, al viajar desde Quinyul hasta el páramo, cambia el espacio que habitaba, modifica su medio ambiente en cuanto al clima, la flora y la fauna, pasando del calor al frío, de la exuberancia vegetal a la parquedad paisajística, de los enormes árboles a los pajonales y frailejones, de la piel sudorosa al viento helado. Su interior, no obstante, permanece intacto: ella, en el páramo, sigue siendo la misma mujer caníbal de poderes sobrenaturales que era desde que salió de Quinyul. No hay ningún factor de tipo psicológico, moral, sentimental ni social que altere el estado en que se encuentra su espíritu. En esta versión, el dinamismo del exterior forma una armonía con la quietud del interior.

Al contrario, en la versión de Reinaldo Arteaga el exterior permanece inmutable mientras el interior se transforma. Aquí La Moledora deja de ser aquella mujer que ayudaba a su comunidad en tiempo de carestía, la que compartía sus cosechas, para convertirse, por cuenta del odio y motivada por la venganza, en una mujer capaz de destruir a los demás sin ningún remordimiento. Ella, en lo que podría considerarse una situación paradójica, deja de alimentar a su sociedad para empezar a alimentarse de esa misma sociedad. Su bondad se convierte en maldad. Pero, a pesar de esta dramática transformación interior, su exterior permanece sin la más mínima alteración. Nunca se mueve del sitio donde siempre ha residido: en el mismo páramo donde compartía sus alimentos, se dedica ahora a comerse a los demás. En esta versión, el dinamismo de su interior forma una armonía con la quietud del exterior.

Esta dualidad entre lo que se transforma y lo inmutable, entre el ser interior y el espacio exterior, nos revela a una mujer en cuyos orígenes hay dos fuerzas que, pese a su oposición, no se repelen ni entran en conflicto. Es posible entender esa dualidad como un fenómeno que revela en la sociedad Pasto un sistema de pensamiento con un fuerte componente incaico.

Pease (1980) y Zuidema (1989) explican que estos sistemas de pensamiento que se caracterizan por la dualidad son, propiamente, una manifestación de la cosmovisión Inca, la cual está presente en gran parte de la geografía andina. De igual modo, Salomón (2011) considera que algunas sociedades precolombinas asentadas en la actual frontera colombo-ecuatoriana estaban influenciados por la cosmovisión dual de los Incas, "en el dominio de las estructuras ideales, como en la administración económica" (p. 375). Las pruebas que presenta se basan en los rasgos de la cerámica, la presencia de términos quechuas, algunos visos de la organización política y algunas alusiones en la ideología cosmológica. Por ello ubica al territorio de los Pastos, que ocupaba todo el páramo y parte del subtrópico, como "el extremo de las tierras altiandinas del Tawantinsuyo" (p. 358), aunque advierte que se trataba de la tierra "más lejana y menos consolidada” (p. 358) de las avanzadas de los Incas.

La investigación geográfica y ecológica que realizó Troll (1958) concluye algo totalmente opuesto. Él considera que no existía una presencia de la cosmovisión Inca en las sociedades precolombinas del páramo y del subtrópico, especialmente en las que actualmente corresponden al sur de Colombia. Su posición se fundamente en que estas sociedades carecían de los logros técnicos en cuanto a manejo de suelos y utilización de herra- 
mientas de mayor rendimiento, elementos que sí aparecen en las demás sociedades donde el Inca había impuesto sus sistemas de pensamiento.

No es el propósito de este trabajo discutir la presencia o ausencia de la cosmovisión Inca en las sociedades precolombinas del páramo y del subtrópico de la actual frontera colombo-ecuatoriana. Lo único que aquí se quiere indicar, como hipótesis, es la posibilidad de que La Moledora, como una manifestación cultural cuyo origen se sitúa en tiempos remotos, presenta rasgos ideológicos que revelan una cosmovisión Inca. Esas dualidades pueden revelar la forma como esas sociedades se organizaban en su estructura social, económica, religiosa y arquitectónica. Definir, a partir del relato de La Moledora, las formas palpables que pudieron haber tomado esas estructuras en el diario vivir es imposible.

Es probable, por otra parte, que el sistema de pensamiento dual que exhibe La Moledora no tenga un origen propiamente incaico, sino que se trate de un fenómeno arraigado en la naturaleza o condición humana. Lévi-Strauss (1995) encuentra ese mismo rasgo en las mitologías y creencias de muchas otras sociedades dispersas por el mundo.

\section{El eco de los mindaláes}

Jorge Mejía, del subtrópico, empieza su versión de La Moledora contextualizando que en el tiempo de antes sus padres y abuelos debían trasladarse a pie hasta el páramo. El viaje, que duraba entre tres y cuatro días, lo realizaban por el lado colombiano de la frontera, siguiendo la trayectoria del río San Juan o el río Plata, porque, supuestamente, por el lado ecuatoriano no existian caminos. Iban cargando a lomo de toro o sobre sus espaldas los quintales repletos de plátanos y yucas que cultivaban. El propósito era vender esos alimentos o cambiarlos para luego retornar por el mismo camino con varios kilos de sal, que “era lo que más necesitábamos” (Vásquez \& Avalos, 2013, p. 138), afirma Jorge Mejía. Siempre, bien fuera de ida o de regreso, caminaban en completo silencio, impidiendo, incluso, que los toros hicieran algún ruido. Luego, al acercarse al sector colombiano de Mayasquer, que limita con el sector ecuatoriano de El Cascarillo, en el páramo, debían arriesgar sus vidas al pasar obligatoriamente por el lugar donde habitaba La Moledora.

Oswaldo Chiles y Reinaldo Arteaga, del páramo, también incluyen en sus relatos de La Moledora descripciones del viaje que realizaban sus padres o abuelos en el tiempo de antes. Cuentan que ellos siempre pasaban por el lugar donde habitaba La Moledora, en las inmediaciones de El Cascarillo o Mayasquer; eso sí, llevando sus alimentos hacia el subtrópico, nunca yendo en busca de los que cultivaban allá. Los lugares que aparecen mencionados son la quebrada del Rosario y el Cerro Negro, como referencias geográficas para la ubicación de los viajeros. Y la ruta utilizada también cruzaba por el territorio colombiano debido a la misma supuesta ausencia de caminos en el lado ecuatoriano de la frontera.

El constante viaje de personas entre el páramo y el subtrópico es un factor común en todas las versiones de La Moledora. Una posible hipótesis para explicar esta característica, bajo un sesgado enfoque histórico, sería la siguiente: la construcción que cada grupo realiza de sí mismos como constantes viajeras refleja el intenso tránsito de personas que en tiempos remotos debió presentarse entre ambas zonas. De hecho, Tapia (1996) explica que, en la época de la Real Audiencia de Quito, las minas de oro y plata descubiertas en Chical, en el subtrópico, "exigían una vía de rápida comunicación con centros poblados con el objeto de lograr mano de obra inmediata para su explotación” (p. 72). Además, mucho antes, en el siglo XIII existían en la actual frontera colombo-ecuatoriana tres rutas altamente transitadas que comunicaban el páramo y el subtrópico: una ruta bordeando el Cumbal, otra bordeando 
el Chiles y la tercera bordeando el Cotacachi (Echeverría \& Uribe, 1995, pp. 448 - 449).

Si es cierto que desde tiempos remotos han existido en la región de la frontera colombo-ecuatoriana varias vías de comunicación altamente transitadas entre el páramo y el subtrópico, entonces ¿por qué razón todos los informantes recalcan en sus historias que la única vía con la cual contaban era la que pasaba por el lado colombiano de la frontera, bordeando las faldas del volcán Chiles?

Este fenómeno, muy probablemente, no es el resultado de un proceso histórico originado en la Conquista; tal vez es reflejo de los problemas de comunicabilidad que empezaron a presentarse en tiempos republicanos en los pueblos de esta zona. Sus caminos ancestrales, debido al cambio en los modos de producción, quedaron en el abandono, destruidos por la corrosión de los suelos o completamente absorbidos por el ímpetu de la naturaleza. Las personas, poco a poco, se sumieron en un aislamiento que les impidió acceder a las tecnologías de la información y la comunicación de la actual sociedad; incluso, muchos de ellos, sobre todo en la parte ecuatoriana de la frontera, nunca llegaron a crear una identificación hacia su país. De ahí que siempre los informantes recalquen en sus relatos que el único camino que les quedaba era el que pasaba por Colombia; una explicación que, a más de indicar que los otros caminos habían desaparecido, muestra la importancia que ha tenido Colombia en la construcción de su imaginario social.

Es posible afirmar, entonces, que el relato de La Moledora evidencia, por un lado, la intensa comunicación que por varios caminos existía entre el páramo y el subtrópico antes y durante la Conquista; y, por otra parte, el aislamiento que empezaron a sufrir estas sociedades en tiempos republicanos, cuando esos caminos desaparecieron y solo quedó el que pasa por Colombia.
Además de estos fenómenos, es posible interpretar otro aspecto en esta parte inicial de $\mathrm{La}$ Moledora: entender a los viajeros del páramo y del subtrópico como un reflejo borroso de los mindaláes, ese grupo de personas privilegiadas que en los tiempos precolombinos dinamizaban la economía de los pueblos indígenas intercambiando "productos de su comunidad de origen, que probablemente provenían del trabajo tributario y del poder productivo de las unidades familiares de los nobles, por otros productos cuya redistribución redundaría en ventajas para el señor patrocinador" (Salomón, 2011, 372).

Por supuesto, sería erróneo afirmar que las versiones de La Moledora ofrecen en los viajeros que se mueven entre el páramo y el subtrópico un retrato de los mindaláes, porque hay muchos aspectos que diferencian claramente a ambos grupos. Por ejemplo, los productos transportados son de diferente naturaleza: los viajeros de La Moledora llevan los alimentos que cultivan; los mindaláes transportaban "productos de primera necesidad para la subsistencia pero, más generalmente, incluían bienes de gran valor unitario" (Salomón, 2011, p. 372). Igualmente, los espacios geopolíticos donde ambos grupos residían presentan grandes diferencias: los viajeros de La Moledora aparecen como habitantes de los centros poblados del páramo o del subtrópico; los mindaláes, por el contrario, residían en sitios que estuvieran entre esos centros poblados, "sitios estratégicamente colocados cerca de las rutas que conectaban las principales zonas ecológicas (valles altos húmedos, valles altos secos, valles transversales semiáridos, montaña)" (Salomón, 2011, p. 373).

Sin embargo, aunque la imagen narrativa de los viajeros de La Moledora no corresponda exactamente a la imagen histórica de los mindaláes, existe entre ambos grupos un mismo factor que los une permitiendo su mutua identificación. Tanto los unos como los otros son protagonistas privilegiados de sus comunidades, grupos cuya principal motivación es el traslado de produc- 
tos culturales para estrechar lazos afectivos con otros pueblos. En este sentido, es posible afirmar que los viajeros de La Moledora son el eco lejano de los mindaláes, un eco que aún resuena en las sociedades de la frontera colombo-ecuatoriana con formas de subsistencia basadas en el intercambio de productos.

\section{La herencia precolombina}

Durante los siglos XVI y XVII, los Pastos se aliaron con las tropas españolas para explotar las minas ubicadas en las llanuras selváticas de la Costa Pacífica. Las enfermedades, las inclemencias del clima y los enfrentamientos con los pueblos indígenas de esa zona, crearon en el imaginario de los Pastos una concepción del subtrópico asociada a la muerte y la destrucción. Esa concepción aún se mantiene vigente a partir de lo que aparece relatado en La Moledora sobre los indígenas Quinyules.

No hay un consenso entre los historiadores y arqueólogos sobre la imposición de la cosmovisión Inca en la sociedad precolombina de los Pastos. Sin embargo, uno de los principales rasgos ideológicos de la cosmovisión Inca, la dualidad, se encuentra presente en la construcción narrativa de La Moledora. Si se asume que este relato proviene de una tradición, entonces es viable adjudicar esa dualidad a una herencia incaica.

Antes de la llegada de los españoles, la sociedad de los Pastos contaba con un grupo de comerciantes denominados mindaláes, los cuales pertenecían a una élite económica. Esos comerciantes pueden ser comparados en cierto modo con los viajeros que aparecen en La Moledora llevando de un lugar a otro sus productos. Se puede, entonces, afirmar que los mindaláes aún permanecen en el imaginario de los actuales Pastos, a pesar de que su rol social desapareció hace más de cuatro siglos.
Estas modelizaciones culturales que se desarrollaron aquí hacen parte de una herencia precolombina que poseen los actuales Pastos. Sin embargo, existen muchos otros factores en $\mathrm{La}$ Moledora que pueden interpretarse como modelizaciones culturales: las relaciones de alteridad, la creación de colectivos, las pruebas shamánicas, los animales sacralizados, las tácticas narrativas y los sistemas religiosos, entre otros. Si el lector desea conocer esas modelizaciones puede consultar otro trabajo más amplio y profundo de los autores, el libro "La Moledora: el último mito de los Pastos”, que será publicado por la editorial Abya-Yala en Ecuador.

\section{Referencias}

Avalos, E., López, L., \& Vásquez, L. (2011). Los saberes de los mayores dibujados por los niños. Quito: Killari.

Borges, J. L. (1989). Obras completas (Vol. II). Buenos Aires: Emecé.

Campo, M. (13 de diciembre de 2009). Condesan. Recuperado el 1 de marzo de 2011, de https://condesan.org/libros/

Echeverría, J., \& Uribe, M. (1995). Área septentrional andina norte: arqueología y etnohistoria. Quito: Abya-Yala.

Eliade, M. (1991). Mitos, sueños y misterios. (M. d. Alburquerque, Trad.) Madrid: Gallimard.

Lévi-Strauss, C. (1995). Antropología estructural. Barcelona: Paidos.

Moya, A. (1999). Ethnos. Atlas mitológico de los pueblos indígenas del Ecuador. Quito: Proyecto Educación Bilingüe Intercultural. 
Ortiz, P., \& Vásquez, L. (s.f.). Tradición oral del cantón Tulcán. Tulcán: Gobierno Municipal del Cantón Tulcán.

Pease, F. (1980). Prólogo. En G. P. Ayala, Nueva coronica y buen gobierno (págs. I-LX). Caracas: Ayacucho.

Salomón, F. (2011). Los señores étnicos de Quito en la época de los Incas. La economía politica de los señoríos norandinos. (G. Ortiz, Trad.) Quito: Instituto Metropolitano de Patrimonio.

Tapia, A. (1996). Expediciones al noroccidente de la Real Audiencia de Quito en los siglos XVI y XVII. Tulcán: La Prensa.

Troll, C. (1958). Las culturas superiores andinas y el medio geográfico. Lima: Universidad Nacional Mayor de San Marcos.

Vásquez, L., \& Avalos, E. (2013). Maldonado contado por los de adelante. Quito: Killari.

Vásquez, L., \& Avalos, E. (2014). Los Pastos y sus historias del Nor-ande. Quito: Killari.

Zuidema, T. (1989). Reyes y guerreros. Ensayos de cultura andina. Lima: Fomciencias. 